\title{
Mental Health, Work Satisfaction and, Quality of Life Among Healthcare Professionals During the COVID-19 Pandemic in an Indonesian Sample
}

\author{
Aulia Iskandarsyah (iD) 1,2 \\ Arina Shabrina (iD) ${ }^{2}$ \\ Achmad Djunaidi ${ }^{1}$ \\ Ahmad Gimmy P Siswadi ${ }^{\prime}$ \\ 'Faculty of Psychology, Universitas \\ Padjadjaran, Bandung, Indonesia; ${ }^{2}$ Center \\ for Psychological Innovation and \\ Research, Universitas Padjadjaran, \\ Bandung, Indonesia
}

\begin{abstract}
Background: During the COVID-19 pandemic, healthcare professionals (HCP) might experience mental health problems and work-related stress, which can lead to less satisfaction at work and decreased health and quality of life in the long period. This study aims to explore the role of mental health and workplace satisfaction on the quality of life in health professionals who are involved in handling the COVID-19 pandemic.
\end{abstract}

Methods: This study was a cross-sectional approach using purposive sampling techniques. The online survey was conducted from May through September 2020. A total of 200 respondents from the West Java province in Indonesia were included. Data on mental health, work satisfaction, and quality of life were analyzed using descriptive statistics, Pearson's correlation coefficient, and multivariate regression analysis. Responses to open questions regarding concerns and strengths were analyzed using thematic analysis.

Results: An increased mental health symptom experienced by healthcare professionals was associated with decreased health status $(\beta=-0.724, \mathrm{p}=0.001)$ and self-perceived health $(\beta=$ $-0.59, \mathrm{p}=0.001)$. Further, serving patients with COVID-19 $(\beta=-0.133, \mathrm{p}=0.024)$ was related to lower health status. Five themes emerged regarding concerns about being exposed to COVID-19, namely 1) fear of transmitting the virus, 2) the impact of COVID-19 on family life, 3) death and isolation, 4) personal safety, and 5) social stigma. Five themes emerged regarding the source of encouragement and strength, ie. 1) religiosity, 2) social support systems, 3) the moral responsibility of the profession, 4) following health and safety protocols, and 5) acceptance and positive attitudes towards the future.

Conclusion: Mental health problems impacted the quality of life. Serving patients with COVID-19 could predict lower health status. HCPs' concerns and sources of strength when exposed to COVID-19 are discussed. Our results give a better understanding of the factors that can decrease and improve HCPs' quality of life, therefore can be used to design psychological interventions to lower HCP's psychological problems and improving their quality of life.

Keywords: COVID-19, mental health, pandemic, quality of life, work satisfaction

\section{Background}

The outbreak of COVID-19 has become a public health emergency of major international concern and has placed unprecedented demands upon healthcare systems worldwide. At the time of preparing this manuscript (April 27, 2020), the World Health Organization reported that there have been recorded 8882 cases and 743 deaths in Indonesia. ${ }^{1}$ During the pandemic, having greater exposure to the virus, perceived risk of infection, shortage of personal protective equipment (PPE),
Correspondence: Aulia Iskandarsyah Faculty of Psychology, Universitas Padjadjaran, Jl. Raya Bandung Sumedang KM 2I, Jatinangor, Bandung, 45363, West Java, Indonesia

Tel $+6281 \quad$ I 2106260

Fax +62 2287920376

Email a.iskandarsyah@unpad.ac.id 
fear of infecting their family at home, inability to disconnect from work, knowing their colleagues contracted the disease, and witnessing death of many patients, colleagues or loved ones became a source of stress for HCPs. ${ }^{2,3}$ They worked under extreme pressures and dealing with difficult decision, and more likely to experience psychological impact of COVID-19 because they are actively involved in dealing with patients and susceptible to a greater risk of developing various mental health problems. ${ }^{4}$

Based on a previous study, among 595 HCPs who had close contact with COVID-19 patients and tested positive with COVID-19 reported a higher symptoms of anxiety and depression compared to the workers who had no unprotected exposure. ${ }^{5}$ A number of studies have recorded the prevalence of various mental health problems faced by HCPs. One systematic review and meta-analysis showed the prevalence for anxiety and depression in HCPs was $23.2 \%$ and $22.8 \%$, respectively. ${ }^{6}$ The incidence of posttraumatic stress symptoms (PTSS) in HCPs who exposed to patients with COVID-19 was $28.7 \%$, while the incidence of PTSS in HCPs who worked in wards for nonCOVID-19 patients was $13.0 \%{ }^{7}$

In addition to mental health problems, a systematic review and meta-analysis using data from previous outbreaks of SARS and MERS showed that about one-third of HCPs experienced burnout syndrome, which very likely will be similar in COVID-19 outbreak. ${ }^{8}$ Besides the high risk of burnout, we also need to pay attention on HCPs' satisfaction about job and work as a critical motivational resource to prevent burnout during the outbreak. ${ }^{9}$ Maintaining a high level of job satisfaction among HCPs is critical to achieving high quality of medical service. ${ }^{10,11}$ HCPs who perceived their work as stressful reported lower satisfaction and added with a higher risk of burnout may have high turnover intentions. ${ }^{12,13}$ Not only caused negative psychological consequences and work-related stress but the COVID-19 pandemic was also associated with impaired health-related quality of life among general residents and HCPs. ${ }^{14,15}$

The well-being and mental health of HCPs are fundamental components of continuing healthcare services during the COVID-19 pandemic. To the best of our knowledge, there are only few systematic studies that explored HCPs' mental health, work satisfaction, and factors related to the quality of life during the COVID-19 pandemic in Indonesia. Understanding the mental health condition among HCPs and factors associated with quality of life will enable the Indonesian government to design psychological interventions for HCPs. Therefore, the research question in this study was what is the relation between mental health, work satisfaction and quality of life among HCPs during COVID-19 pandemic?

\section{Methods \\ Study Design and Participants}

This study was a cross-sectional approach using purposive sampling. The population in this study was HCPs who were involved in handling the COVID-19 pandemic in West Java Province. Considering the unknown population number, we did a theoretical calculation that the number of HCPs involved in handling the pandemic and reachable is 10,000 . Using $95 \%$ confidence level and 5\% margin of error, we obtained 370 for sample size. Participants were selected according to the criteria to meet the research needs. The inclusion criteria for study participants were 1) healthcare professionals consisting of general practitioners, medical specialists, residents, nurses, laboratory staff, and other medical staff; 2) involved in handling the COVID-19 pandemic at health centers in the West Java region; and 3) willing to participate as participants. A total of 379 participants accessed the link and filled the survey. However, 179 data were excluded because they were not complete. A total of $200 \mathrm{HCPs}$ were included in this study.

\section{Data Collection}

Ethical approval was obtained from the Research Ethics Committee of Universitas Padjadjaran, Indonesia (Reference Number No. 487/UN6.KEP/EC/2020). The study was conducted in accordance with the Declaration of Helsinki. We conducted a web-based survey from May through September 2020. First, we constructed instruments to obtain information on the demographic background, create open-ended questions, and used existing scales to measure mental health condition, work satisfaction, and quality of life. Participants were recruited through the internet by spreading a survey link to HCPs who work at various healthcare centers or treatment centers of COVID19 in West Java Province. The participants completed an online questionnaire using SurveyMonkey platform. The researchers provided a reward in the form of an e-money of IDR 50,000 (USD 3.5) to participants who have participated in the research process. All participants were voluntarily responded to the anonymous survey and provide their consent online on the first page of the survey. 


\section{Survey Instruments}

A standard socio-demographic form was used to collect self-report data on age, gender, region of residence, educational level, monthly income, work placement, and profession. We used a questionnaire that asked about the following areas: 1) demographic data, 2) mental health condition (depression, anxiety, somatoform disorders, and PTSD symptoms), 3) work satisfaction, 4) quality of life, and 5) two open questions regarding their concern when exposed to COVID-19 and the things that encourage or strengthened them in this situation.

\section{Self-Reporting Questionnaire (SRQ)}

The SRQ was developed by the WHO as an instrument for screening mental disorders, including depression, anxietyrelated disorders, and somatoform disorders. The SRQ consists of 20 items that use "yes" or "no" answer options (if the participants think the questions apply to them, they can choose "yes" and if it does not apply to them, choose "no"). SRQ-20 has a good internal reliability $(\alpha=0.78)$. Factor analysis yielded two factors, explaining $31.2 \%$ of the total variance. This instrument performs well in detecting generalized mental disorders, with an area under the curve (AUC) of 0.879 (SE = $0.23,95 \%$ CI $0.83-0.92$ ) for the overall sample and with an optimal cut-off score of $5 / 6$ and a sensitivity of $78.6 \%$ and specificity of $81.5 \%{ }^{16}$ We also added five items to measure PTSD symptoms related to COVID-19 over the course of 1 month using yes/no answer options (higher scores indicate more severe PTSD symptoms).

\section{Work Satisfaction}

We developed a work satisfaction scale in the COVID-19 context consisted of three subscales namely personal safety at the workplace, serving patients with COVID-19, and comfortable working situations. Personal safety at workplace subscale assessed the perceived safety provided in the workplace including the availability of personal protective equipment, appropriate schedule, enough rest time, and meals that meet daily nutritional needs, serving patients with COVID-19 subscale examined participant's perception about caring for COVID-19 patients, and comfortable working situation subscale evaluated participant's view about their workplace and its management. The three subscales were measured by nine items with each subscale has three items. Participants were asked to answer on a 5-point response scale, ranged from 1 (strongly disagree) to 5 (strongly agree). The total score was obtained by summing the scores from each item in the questionnaire.
Response scales of items 1,4 , and 8 were reserved for obtaining the same response direction as other items. A higher score indicates higher work satisfaction.

\section{EQ-5D-5L}

The EQ-5D-5L is a standard instrument developed by the EuroQol Group is a health-related quality of life measure that can be used in a variety of health conditions and treatments. EQ-5D-5L consisted of a descriptive system and EQ-VAS. The descriptive system consists of five dimensions: mobility, self-care, daily activities, pain/discomfort, and anxiety/depression. Each dimension has 5 levels: no problem, slight problem, moderate problem, severe problem, and extreme problem. The EQ-VAS recorded the patient's health self-assessment on a vertical visual analog scale. We used two outputs from EQ-5D-5L to describe individuals' health status, namely index score and EQ-VAS. The test-retest reliability of the five dimensions of the EQ-5D-5L showed a near-perfect agreement between the two tests (Gwet's AC: 0.85-0.99 and percentage agreement: $90-99 \%){ }^{17}$

\section{Open Questions}

Participants were asked two open-ended questions regarding their concerns when exposed to COVID-19 (What are the things that concerned you the most when exposed to COVID-19?) and the things that strengthen or encourage them in this situation (What are the things that encourage or strengthen you in this situation?). We asked these questions to get an insight regarding HCPs' experiences in dealing with the COVID-19 pandemic. Their concerns and source of strengths can give additional information to the studied variables.

\section{Data Analysis}

Data analyses were carried out using the IBM SPSS Statistics version 24. Before analyzing the data, data screening was carried out to ensure all the data were complete and had a good quality. Descriptive statistics were used to describe the demographic of the study participants, the SRQ, the workplace satisfaction scale, and the EQ-5D-5L scores (mean and standard deviation). Associations between demographic variables and, the SRQ, the workplace satisfaction scale, and the EQ-5D$5 \mathrm{~L}$ scores were analyzed by the independent $t$-test for a variable with two categories and ANOVA for variables with two categories or more. The following demographic variables were categorized: gender (male vs female), 
workplace (COVID-19 referral hospital vs non-referral hospital for COVID-19 vs public health center vs others), and profession (doctor and medical specialist vs nurses vs others). Associations among the SRQ, the workplace satisfaction scale, and the EQ-5D-5L scores were explored by Pearson's product-moment correlation coefficient. We used a multiple regression analysis to see which variables serve as predictors of the respondent's quality of life. Mental health and work satisfaction were set as independent variables and the quality of life was the dependent variable. We did not apply a separate analysis on the different levels of demographic or include those as an interaction term. Further, omega squared $\left(\omega^{2}\right)$ effect size was calculated for all comparisons, with $\omega^{2}=0.010, \omega^{2}=$ 0.059 , and $\omega^{2}=0.138$ demonstrating a small, medium, and large effect size, respectively. ${ }^{18}$ All tests were two-tailed, with a significance level of $\mathrm{p}<0.05$.

The answers to the open-ended questions were analyzed using a thematic analysis approach to provide relevant themes. Guidelines for thematic analysis and qualitative software program NVivo version 11 were used. ${ }^{19}$ The data analysis process started with two independent coders who read all the answer documents from the participants and built the initial coding directory. Using this initial directory, each coder provided a separate transcript code. The discussion was held to reach an agreement on the differences in the initial coding. The codes were structured into potential themes to produce a thematic map of the analysis. Finally, the discussion was held again to produce a definition and name for each theme. The frequencies for each theme and sub-theme were counted and typical citations recorded.

\section{Results}

Table 1 described the demographic characteristics of the study participants. The ages of HCPs ranged from 22 to 57 years $(\mathrm{M}=36.65, \mathrm{SD}=8.56)$. Most of the healthcare professionals were female, lived in the city, and have completed their bachelor's degrees. The majority of them worked in a COVID-19 referral hospital. The top five professions in the HCPs were nurses, pharmacists, general practitioners, medical specialists, and laboratory assistants.

\section{HCPs' Mental Health Condition, Work Satisfaction, and Quality of Life}

Table 2 shows the mean, standard deviations, and ranges of the SRQ, the Work Satisfaction Scale, and the EQ-5D5L scores. Mental health and PTSD symptom scores were
Table I Demographic Characteristics of Study Participants

\begin{tabular}{|c|c|c|c|}
\hline Variable & & \multicolumn{2}{|c|}{ n (\%) } \\
\hline Age $(M \pm S D)$ & & \multicolumn{2}{|c|}{$36.65 \pm 8.56$} \\
\hline \multirow[t]{2}{*}{ Gender } & Female & 142 & (7I) \\
\hline & Male & 58 & (29) \\
\hline \multirow[t]{2}{*}{ Residence } & City & 107 & $(53.5)$ \\
\hline & Districts & 93 & $(46.5)$ \\
\hline \multirow[t]{5}{*}{ Education level } & High school/Vocational school & 1 & $(0.5)$ \\
\hline & Associate degree & 50 & $(25)$ \\
\hline & Bachelor's degree & 113 & $(56.5)$ \\
\hline & Master's degree & 32 & $(16)$ \\
\hline & Doctoral degree & 4 & $(2)$ \\
\hline \multirow{5}{*}{$\begin{array}{l}\text { Monthly } \\
\text { income }\end{array}$} & Have no income & 4 & $(2)$ \\
\hline & $\begin{array}{l}\text { Less than IDR } 2.500 .000 \text { (<USD } \\
\text { I } 78)\end{array}$ & 3 & $(1.5)$ \\
\hline & $\begin{array}{l}\text { IDR 2.500.000-5.000.000 (USD } \\
\text { I78-357) }\end{array}$ & 74 & (37) \\
\hline & $\begin{array}{l}\text { IDR } 5.000 .000-\operatorname{Rp} 10.000 .000 \\
\text { (USD 357-7|4) }\end{array}$ & 81 & $(40.5)$ \\
\hline & $\begin{array}{l}\text { More than IDR I0.000.000 (>USD } \\
7 \mid 4)\end{array}$ & 38 & (19) \\
\hline \multirow[t]{8}{*}{ Workplace } & COVID-19 referral hospital & 117 & $(58.5)$ \\
\hline & $\begin{array}{l}\text { Non-referral hospital for COVID- } \\
19\end{array}$ & 27 & $(13.5)$ \\
\hline & Public health center & 35 & $(17.5)$ \\
\hline & Clinic & 12 & $(6)$ \\
\hline & Independent practice & 1 & $(0.5)$ \\
\hline & $\begin{array}{l}\text { West Java Province Independent } \\
\text { Isolation Center }\end{array}$ & 4 & $(2)$ \\
\hline & Pharmacy & 3 & $(1.5)$ \\
\hline & Public Health Office & I & $(0.5)$ \\
\hline \multirow[t]{14}{*}{ Profession } & Medical specialist & 17 & $(8.5)$ \\
\hline & General practitioner & 32 & $(16)$ \\
\hline & Specialist nurse & 5 & $(2.5)$ \\
\hline & Nurse & 70 & (35) \\
\hline & Pharmacist & 42 & $(21)$ \\
\hline & Laboratory assistant & 7 & (3.5) \\
\hline & Residents doctor & 3 & $(1.5)$ \\
\hline & Clinical psychologist & 2 & $(1)$ \\
\hline & Midwife & 7 & (3.5) \\
\hline & Hospital Management/ & 5 & $(2.5)$ \\
\hline & Administration & & \\
\hline & Dentist & 3 & $(1.5)$ \\
\hline & Nutritionist & 4 & $(2)$ \\
\hline & Radiographer/Physiotherapy Staff & 3 & $(1.5)$ \\
\hline
\end{tabular}

Abbreviations: $N$, number of participant; M, mean; SD, standard deviation; IDR, Indonesian Rupiah; USD, US dollar.

positively skewed, QoL Index score and EQ-VAS scores were negatively skewed, whereas all work satisfaction subscales were normally distributed. 
Table 2 Descriptive Statistics of the SRQ, PTSD Symptoms, Work Satisfaction Scale, and the EQ-5D-5L Scores

\begin{tabular}{|c|c|c|c|c|c|}
\hline Measure & Dimension & Mean & SD & Min & $\operatorname{Max}$ \\
\hline Mental Health & & 3.64 & 3.70 & 0 & 16 \\
\hline PTSD Symptoms & & 1.27 & 1.32 & 0 & 5 \\
\hline \multirow[t]{4}{*}{ Work Satisfaction } & & & & & \\
\hline & Personal Safety & 9.37 & 1.84 & 3 & 15 \\
\hline & $\begin{array}{l}\text { Serving Patients with } \\
\text { COVID-19 }\end{array}$ & 11.36 & 1.68 & 7 & 15 \\
\hline & $\begin{array}{l}\text { Comfortable Working } \\
\text { Situation }\end{array}$ & 11.00 & 1.92 & 4 & 15 \\
\hline \multirow[t]{2}{*}{ Quality of Life } & Index Score & 0.93 & 0.08 & 0.69 & 1.00 \\
\hline & EQ-VAS & 87.95 & 9.79 & 45 & 100 \\
\hline
\end{tabular}

Abbreviations: PTSD, post-traumatic stress disorder; EQ-VAS, EQ visual analog scale; M, mean; SD, standard deviation; Min, minimum; Max, maximum.

\section{Association Between Demographic Variables, Mental Health, PTSD Symptoms, Work Satisfaction, and Quality of Life}

Gender was not significantly associated with a mental health condition, PTSD symptoms, work satisfaction, and quality of life. QoL (index score) showed a significant difference based on workplace $(F(3,196)=2.71, \mathrm{p}=$ 0.046). HCPs who work in COVID-19 referral hospitals had significantly lower scores on QoL $(0.925 \pm 0.083$, $\mathrm{p}=$ 0.027) compared to HCPs who work in other healthcare facilities $(0.964 \pm 0.066)$. PTSD symptoms revealed a statistically significant difference based on the type of healthcare profession $(F(2,197)=4.75, \mathrm{p}=0.01)$. Nurses $(1.02 \pm 1.25, \mathrm{p}=0.033)$ and others HCPs $(1.07 \pm 1.25$, $\mathrm{p}=0.025$ ) showed statistically significantly lower PTSD symptoms compared to doctor and medical specialist (1.63 \pm 1.3$)$. According to the power calculation, we obtained a small effect size for both significant comparisons $\left(\omega^{2}=0.025\right.$ and $\left.\omega^{2}=0.036\right)$.

Table 3 shows the Pearson's product-moment correlation coefficients of all variables. We found mental health condition such as depression, anxiety, and somatoform disorders was positively correlated with PTSD symptoms $(r=0.52, \mathrm{p}=0.001)$, while subscales of work satisfaction, ie, personal safety, serving patients with COVID-19, comfortable working condition, health status (index score), and self-perceived health (EQ-VAS) were negatively correlated. PTSD symptoms were negatively correlated with all subscales of work satisfaction and quality of life.

Multiple Regression Analysis showed that mental health, PTSD symptoms, and work satisfaction subscales explain a significant amount of the variance in the health status variable, $F(5194)=37.93, \mathrm{p}<0.05, R^{2}=0.494$ (Model 1). As presented in Table 4, an increased mental health symptom experienced by HCPs was associated with decreased health status $(\beta=-0.724, p=0.001)$. Further, serving patients with COVID-19 $(\beta=-0.133, \mathrm{p}=0.024)$ was related to lower health status. We also found that mental health, PTSD symptoms, personal safety, serving patients with COVID-19, and comfortable working situation explain a significant amount of the variance in selfperceived health, $F(5194)=21.11, \mathrm{p}<0.05, R^{2}=0.352$ (Model 2). A worsen mental health condition among health professionals was associated with decreased self-perceived health $(\beta=-0.59, \mathrm{p}=0.000)$.

Table 3 Pearson's Product-Moment Correlation of the Mental Health, PTSD Symptoms, Work Satisfaction, and Quality of Life

\begin{tabular}{|l|c|c|c|c|c|c|}
\hline Measure & $\mathbf{2}$ & $\mathbf{3}$ & $\mathbf{4}$ & $\mathbf{5}$ & $\mathbf{6}$ & $\mathbf{7}$ \\
\hline I. Mental Health & $0.52^{* *}$ & $-0.35^{* *}$ & $-0.4^{* *}$ & $-0.41^{* *}$ & $-0.68^{* *}$ & $-0.59^{* *}$ \\
\hline 2. PTSD Symptoms & & $-0.26^{* *}$ & $-0.28^{* *}$ & $-0.29^{* *}$ & $-0.37^{* *}$ & $-0.28^{* *}$ \\
\hline 3. Personal Safety & & & $0.31^{* *}$ & $0.401^{* *}$ & $0.16^{*}$ & $0.22^{* *}$ \\
\hline 4. Serving Patients with COVID-19 & & & & $0.405^{* *}$ & $0.17^{*}$ & $0.27^{* *}$ \\
\hline 5. Comfortable Working Situation & & & & & $0.301^{* *}$ & $0.267^{* *}$ \\
\hline 6. Index Score & & & & & & $0.507^{* *}$ \\
\hline 7. EQ-VAS & & & & & \\
\hline
\end{tabular}

Notes: $*_{p}<0.05 ; * * p<0.01$.

Abbreviations: PTSD, post-traumatic stress disorder; EQ-VAS, EQ visual analog scale. 
Table 4 Summary of Multiple Regression Analysis for the Prediction of Index Score and EQ-VAS

\begin{tabular}{|l|c|c|c|c|c|c|c|}
\hline Independent Variable & $\mathbf{B}$ & $\mathbf{S E}$ & $\boldsymbol{\beta}$ & $\boldsymbol{t}$ & $\boldsymbol{P}$ & $\boldsymbol{R}^{\mathbf{2}}$ & ${\text { Adjusted } \boldsymbol{R}^{\mathbf{2}}}$ \\
\hline Model I: Index score as DV & & & & & & 0.49 & 0.48 I \\
\hline Mental Health (SRQ) & -0.016 & 0.001 & $-\mathbf{0 . 7 2 4}$ & -10.9 & $\mathbf{0 . 0 0 I}$ & & \\
PTSD symptoms & -0.002 & 0.004 & -0.033 & -0.53 & 0.592 & \\
Personal Safety & -0.004 & 0.003 & -0.095 & -1.63 & 0.103 & \\
Serving Patients with COVID-19 & -0.007 & 0.003 & $-\mathbf{0 . 1 3 3}$ & -2.26 & $\mathbf{0 . 0 2 4}$ & & \\
Comfortable Working Situation & 0.003 & 0.003 & 0.079 & 1.309 & 0.192 & & \\
\hline Model 2: EQ-VAS as DV & & & & & & 0.35 & \\
\hline Mental Health (SRQ) & -1.56 & 0.198 & $-\mathbf{0 . 5 9 1}$ & -7.90 & $\mathbf{0 . 0 0 1}$ & & \\
PTSD symptoms & 0.298 & 0.507 & 0.040 & 0.587 & 0.558 & & \\
Personal Safety & 0.047 & 0.348 & 0.009 & 0.134 & 0.893 & & \\
Serving Patients with COVID-19 & 0.182 & 0.388 & 0.031 & 0.470 & 0.639 & & \\
Comfortable Working Situation & 0.073 & 0.350 & 0.014 & 0.209 & 0.834 & & \\
\hline
\end{tabular}

Note: Bold, $p<0.05$.

Abbreviations: DV, dependent variable; SRQ, Self-Reporting Questionnaire; PTSD, post-traumatic stress disorder; EQ-VAS, EQ visual analog scale; B, the unstandardized beta; SE, the standard error for the unstandardized beta; $\beta$, the standardized beta; $t$-test statistic; $\mathrm{p}$, the probability value; $R^{2}, R$-squared.

\section{Thematic Analysis results of Health Professionals Concern and Source of Strengths}

We explore the concern of HCPs when exposed to COVID-19 and the things that encourage and strengthen health workers in a pandemic situation. Five themes emerged regarding HCP's concerns when exposed to COVID-19, namely:

1. Fear of transmitting the virus to others. A large number of participants expressed concern about transmitting the virus to their families and loved ones, especially children at home.

2. Impact of COVID-19 on family life. Most of the participants were worried because they could not stay together with their family, left them, and unable to go home to meet their family members, especially children, and spouse.

3. Death and isolation. Most of the participants stated that their biggest concern was death. Some of the participants also explained a condition that provokes feelings of worry, with the phrase 'die in isolation.

4. Personal safety. Most of the participants were afraid of contracting COVID-19, which could cause severe symptoms and worsen their health conditions. Some participants were more susceptible to infection due to age and the illness they suffered.

5. Social stigma. Participants expressed fear of getting stigma from other people and their social environment. The form of discrimination included isolating, alienating, and staying away from people who were 'suspected to have the potential to spread the virus.

Furthermore, five themes also emerged regarding the things that encourage and strengthen them during the pandemic, namely:

1. Religiosity. The majority of participants believed that the current situation was a destiny from God that deserves to be accepted, lived, and there was a lesson from this incident.

2. Social support system. Family, parents, spouses, and children prayed regularly and provided support by calming them, understanding their obstacles at work, and motivated them.

3. Moral responsibility of profession. The majority of participants viewed their role during the pandemic had become their obligation and responsibility as HCPs. Professionalism as a healthcare worker, awareness of job risks, and professional demands encouraged participants to always be prepared in various situations.

4. Following COVID-19 health and safety protocols. Most of the participants stated the availability of PPE (personal protective equipment), wearing PPE during work, maintaining immunity, and following health, protocols were the things that strengthened them in this situation.

5. Acceptance and positive attitudes towards the future. The current pandemic was seen as an inevitable situation that has to be accepted; moreover, participants explained that the ways to make 
themselves stronger were by think positively, maintain enthusiasm, and try to go through the day as usual.

\section{Discussion}

The present study is among the first to explore mental health, PTSD symptoms, work satisfaction, and quality of life among HCPs during COVID-19 in the Indonesian population. Health status showed a significant difference based on workplace, while PTSD symptoms differ on doctor and specialist, nurses, and other professionals. HCPs who work in COVID-19 referral hospitals had a lower health status compared to HCPs who work in other healthcare facilities. Healthcare professionals who actively dealt with COVID-19 might be exposed to much more physical and mental stresses due to higher workload and risk of exposure and longer stay in hospitals to provide care for the patients. ${ }^{20,21}$

Doctors and medical specialists experienced more severe PTSD symptoms compared to nurses and other HCPs. At the time of the COVID-19 outbreak, many HCPS were infected, which may escalate the psychological distress of their colleagues. ${ }^{22}$ They might experience existential stress and the pain of losing patients and colleagues, all in addition to the infection risk. ${ }^{23}$ Seeing colleagues who lost their lives because of a pandemic can be a traumatic and dehumanizing experience.

We found that mental health problems among HCPs will increase the likelihood of developing PTSD symptoms. A harsh environment, depressing setting, witnessing death, and workload pressure during a pandemic can threaten lives and impose psychological trauma on HCPs and increase their sensitivity to PTSD. ${ }^{24}$ Mental health problems such as anxiety and depression were highly correlated with PTSD symptoms in HCPs working directly with COVID-19 patients. $^{25}$ Their work situation will constantly put them in a challenging and stressful situation. Watching the spike number of infected patients, merciless and isolated death caused by COVID-19, the lack of human and technical resources could potentially make HCPs developing PTSD. ${ }^{26}$

Increased mental health problems experienced by HCPs were associated with decreased health status and perceived overall health. Mental health problems among HCPs might be associated with burnout symptoms, which can explain their poor perceived health. An earlier study showed that HCPs in Indonesia who had direct contact or treat COVID-19 patients exhibit a higher risk for anxiety, depression, and burnout symptoms. ${ }^{27}$ Perceived health and health-related quality of life were worse among HCPs that experienced excessive occupational stress and reported a high level of emotional, mental, and physical exhaustion. $^{28-30}$ HCPs experienced high work-related stress, with an imbalance between high effort and low rewards, they were less able to do activities that promote resilience, they also reported insomnia, anxiety and depression, which all of these can contribute to poorer health and lower quality of life. ${ }^{31}$

Further, perception about serving patients with COVID-19 was related to lower health status. HCPs work consists of providing direct care to individuals with a variety of health needs and oftentimes they witness patients' pain and suffering. This condition can make HCPs had a negative experience known as compassion fatigue, which was associated with perceived stress among HCPs. ${ }^{32}$ HCPs who experienced compassion fatigue felt like they began to distance themselves from the suffering of patients and families.

Factors related to mental health problems among HCPs were reflected in themes regarding their concern when exposed to COVID-19. HCPs felt fear of transmitting COVID-19 to their family and others, afraid of contracting the virus themselves, thought about the death, being isolated from their family and other people, and worried about being ostracized by others. All of these combined might make HCPs experience distress constantly both at home and work. These findings are following a previous study that found that HCPs experienced constant anxiety about virus transmission to their families because they work in a place with a high risk of infection. ${ }^{33}$ They also feared being infected by the virus because they work closely with the patients and some patients may not present with symptoms. ${ }^{34,35}$

For HCPs in our study, sources of encouragement and strengths for HCPs were religiosity, strong social support systems, the moral responsibility of profession, following COVID-19 health and safety protocols, acceptance, and positive attitudes towards the future. Indonesians are well known for their religiosity. ${ }^{36}$ Religion seems to influence how HCPs explain pandemics ("Pandemic is a fate from God") and their coping skill. Religious faith and practice can have a role in supporting individuals to develop more positive emotions, which later help to boost their immune system and moderate the effects of infection. ${ }^{37}$ Further, it is well recognized that prayer is 
a common way of dealing with adversity and many people had prayed for the pandemic to end. ${ }^{38}$ We suggest that the religiosity theme may be related to acceptance and a positive attitude towards the future. HCPs viewed pandemics as something inevitable and need to be accepted. This viewpoint can look quite similar to the concept of "fate" as some events happen beyond one's control.

Social support received by HCPs makes them feel calmer, understood, and cared for by their closest ones. This result in line with previous studies demonstrated that social support was negatively correlated with mental health problems such as depression and anxiety, loneliness, and sleeping troubles during COVID-19. ${ }^{39-42}$

\section{Limitation}

This study has several limitations that should be considered when interpreting the findings. The data have been obtained from a cross-sectional design study, which does not allow a causal relationship between variables and the change of the study variables over time. In our study, the relatively high data exclusion was due the length of the survey; therefore, some participants did not finalize the submission. We recommend a shorter version of survey required to fill in responses to all questions. The sample size of this study can be larger to ensure generalization and is needed to verify the results. Further longitudinal studies will provide a deeper understanding of the impact of mental health on work satisfaction and quality of life in the course of the pandemic.

\section{Conclusions}

Healthcare professionals who work in COVID-19 referral hospitals had a lower health status. Doctors experience more severe PTSD symptoms. A worsen mental health condition was associated with lower health status and self-perceived overall health. The main concerns for HCPs who directly handling COVID-19 were fear of transmission and infection, death, isolation, and social stigma. The sources of encouragement and strengths for HCPs were religiosity, strong social support systems, the moral responsibility of profession, following COVID-19 health and safety protocols, acceptance, and positive attitudes towards the future. Our results give a better understanding of the factors that can decrease and improve HCPs' quality of life, therefore can be used to design psychological interventions to lower HCP's psychological problems and improving their quality of life.

\section{Abbreviations}

ANOVA, analysis of variance; COVID-19, coronavirus disease; DV, dependent variable; EORTC QLQ-C30, European Organisation for Research and Treatment of Cancer Quality of Life Questionnaire-Core 30; EQ-5D, EuroQol five-dimension scale; EQ-5D-5L, The 5-level EQ-5D version; EQ-VAS, EQ visual analog scale; HCP, healthcare professionals; SPSS, Statistical Package for the Social Sciences; IDR, Indonesian Rupiah; PPE, personal protective equipment; PTSD, post-traumatic stress disorder; QoL, quality of life; SARS, severe acute respiratory syndrome; SD, standard deviation; SRQ, Self-Reporting Questionnaire; USD, US dollar; WHO, World Health Organization.

\section{Data Sharing Statement}

All data generated and analyzed during the current study are available from the corresponding author on reasonable request.

\section{Ethics Approval and Informed Consent}

This study was reviewed and approved by the Research Ethics Committee of Universitas Padjadjaran, Indonesia, No. 487/UN6.KEP/EC/2020. All participants were informed of the research process and provided digital informed consent included publication of anonymized responses.

\section{Acknowledgments}

The authors would like to thank all participants for their generous participation in this study. This research was funded by COVID-19 Research Grant from Universitas Padjadjaran, grant number 1568/UN6.3.1/LT/2020.

\section{Author Contributions}

All authors made substantial contributions to conception and study design, data collection, analysis and interpretation of data; took part in drafting and revising the article or critically reviewed for the content; agreed to submit to the current journal; gave final approval for the version to be published; and agreed to take responsibility and be accountable for the content of the article.

\section{Disclosure}

The authors declare no conflicts of interest for this work. 


\section{References}

1. World Health Organization. Indonesia: WHO Coronavirus Disease (COVID-19). WHO; 2020.

2. Mira JJ, Carrillo I, Guilabert M, et al. Acute stress of the healthcare workforce during the COVID-19 pandemic evolution: a cross-sectional study in Spain. BMJ Open. 2020;10:e042555. doi:10.1136/bmjopen-2020-042555

3. Zaka A, Shamloo SE, Fiorente P, Tafuri A. COVID-19 pandemic as a watershed moment: a call for systematic psychological health care for frontline medical staff. $J$ Health Psychol. 2020;25(7):883-887. doi:10.1177/1359105320925148

4. Spoorthy MS, Prtapa SK, Mahant S. Mental health problems faced by healthcare workers due to the COVID-19 pandemic-a review. Asian $J$ Psychiatr. 2020;51:102119. doi:10.1016/j.ajp.2020.102119

5. Magnavita N, Tripepi G, Di Prinzio R. Symptoms in health care workers during the COVID-19 epidemic. A cross-sectional survey. Int J Environ Res Public Health. 2020;17(14):1-15. doi:10.3390/IJERPH17145218

6. Pappa S, Ntella V, Giannakas T, Giannakoulis V, Papoutsi E, Katsaounou P. Prevalence of depression, anxiety, and insomnia among healthcare workers during the COVID-19 pandemic: a systematic review and meta-analysis. Brain Behav Immun. 2020;88:901-907. doi:10.1016/J.BBI.2020.05.026

7. Chen H, Wang B, Cheng Y, et al. Prevalence of posttraumatic stress symptoms in health care workers after exposure to patients with COVID-19. Neurobiol Stress. 2020;13:100261. doi:10.1016/J. YNSTR.2020.100261

8. Magnavita N, Chirico F, Garbarino S, Bragazzi N, Santacroce E, Zaffina S. SARS/MERS/SARS-CoV-2 outbreaks and burnout syndrome among healthcare workers. An umbrella systematic review. Int J Environ Res Public Health. 2021;18(8):4361. doi:10.3390/IJERPH18084361

9. Zhang SX, Huang H, Wei F. Geographical distance to the epicenter of Covid-19 predicts the burnout of the working population: ripple effect or typhoon eye effect? Psychiatry Res. 2020;288:112998. doi:10.1016/j.psychres.2020.112998

10. Kabbash IA, El-Sallamy RM, Abdo SAEF, Atalla AO. Job satisfaction among physicians in secondary and tertiary medical care levels. Environ Sci Pollut Res. 2020;27:37565-37571. doi:10.1007/s11356020-08506-9

11. Semachew A, Belachew T, Tesfaye T, Adinew YM. Predictors of job satisfaction among nurses working in Ethiopian public hospitals, 2014: institution-based cross-sectional study. Hum Resour Health. 2017;15(31):1-8. doi:10.1186/s12960-017-0204-5

12. Itzhaki M, Bluvstein I, Bortz AP, et al. Mental health nurse's exposure to workplace violence leads to job stress, which leads to reduced professional quality of life. Front Psychiatry. 2018;9(59):1-6. doi:10.3389/fpsyt.2018.00059

13. Wang H, Jin Y, Wang D, Zhao S, Sang X, Yuan B. Job satisfaction, burnout, and turnover intention among primary care providers in rural China: results from structural equation modeling. BMC Fam Pract. 2020;21(12):1-10. doi:10.1186/s12875-020-1083-8

14. Stojanov J, Malobabic M, Stanojevic G, Stevic M, Milosevic V, Stojanov A. Quality of sleep and health-related quality of life among health care professionals treating patients with coronavirus disease-19. Int J Soc Psychiatry. 2021;67(2):175-181. doi:10.1177/ 0020764020942800

15. Zhang Y, Ma Z. Impact of the COVID-19 pandemic on mental health and quality of life among local residents in Liaoning Province, China: a cross-sectional study. Int $J$ Environ Res Public Health. 2020;17:2381. doi:10.3390/ijerph17072381

16. Netsereab TB, Kifle MM, Tesfagiorgis RB, Habteab SG, Weldeabzgi YK, Tesfamariam OZ. Validation of the WHO self-reporting questionnaire-20 (SRQ-20) item in primary health care settings in Eritrea 11 Medical and Health Sciences 1117 Public Health and Health Services. Int J Ment Health Syst. 2018;12(1):1-9. doi:10.1186/s13033-018-0242-y
17. Purba FD, Hunfeld JAM, Iskandarsyah A, et al. Quality of life of the Indonesian general population: test-retest reliability and population norms of the EQ-5D-5L and WHOQOL-BREF. PLoS One. 2018;13 (5):e0197098. doi:10.1371/journal.pone.0197098

18. Kotrlik JW, Williams HA. The incorporation of effect size in information technology, learning, and performance research. Inf Technol Learn Perform J. 2003;21(1):1.

19. Braun V, Clarke V. Using thematic analysis in psychology. Qual Res Psychol. 2006;3(2):77-101. doi:10.1191/1478088706qp063oa

20. Cai Q, Feng H, Huang J, et al. The mental health of frontline and non-frontline medical workers during the coronavirus disease 2019 (COVID-19) outbreak in China: a case-control study. J Affect Disord. 2020;275:210-215. doi:10.1016/j.jad.2020.06.031

21. Liu Z, Han B, Jiang R, et al. Mental health status of doctors and nurses during COVID-19 epidemic in China. 2020.

22. Wang D, Hu B, Hu C, et al. Clinical characteristics of 138 hospitalized patients with 2019 novel coronavirus-infected pneumonia in Wuhan, China. JAMA - J Am Med Assoc. 2020;323(11):1061-1069. doi:10.1001/jama.2020.1585

23. The Lancet. COVID-19: protecting health-care workers. Lancet. 2020;395(10228):922. doi:10.1016/S0140-6736(20)30644-9

24. Tang L, Pan L, Yuan L, Zha L. Prevalence and related factors of post-traumatic stress disorder among medical staff members exposed to H7N9 patients. Int J Nurs Sci. 2017;4(1):63-67. doi:10.1016/j. ijnss.2016.12.002

25. Johnson SU, Ebrahimi OV, Hoffart A. PTSD symptoms among health workers and public service providers during the COVID-19 outbreak. PLoS One. 2020;15(10):e0241032. doi:10.1371/journal.pone.0241032

26. Dutheil F, Mondillon L, Navel V. PTSD as the second tsunami of the SARS-Cov-2 pandemic. Psychol Med. 2021;51:1773-1774. doi:10.1017/S0033291720001336

27. Sunjaya DK, Herawati DMD, Siregar AYM. Depressive, anxiety, and burnout symptoms on health care personnel at a month after COVID-19 outbreak in Indonesia. BMC Public Health. 2021;21 (1):1-12. doi:10.1186/s12889-021-10299-6

28. Korkmaz S, Kazgan A, Çekiç S, Tartar AS, Balcı HN, Atmaca M. The anxiety levels, quality of sleep and life and problem-solving skills in healthcare workers employed in COVID-19 services. $J$ Clin Neurosci. 2020;80:131-136. doi:10.1016/j.jocn.2020.07.073

29. Sarafis P, Rousaki E, Tsounis A, et al. The impact of occupational stress on nurses' caring behaviors and their health related quality of life. BMC Nurs. 2016;15(56):1-9. doi:10.1186/s12912-016-0178-y

30. Suñer-Soler R, Grau-Martín A, Font-Mayolas S, Gras ME, Bertran C, Sullman MJM. Burnout and quality of life among Spanish healthcare personnel. J Psychiatr Ment Health Nurs. 2012;20(4):305-313. doi:10.1111/j.1365-2850.2012.01897.x

31. Magnavita N, Soave P, Ricciardi W, Antonelli M. Occupational stress and mental health among anesthetists during the COVID-19 pandemic. Int $J$ Environ Res Public Health. 2020;17(21):1-14. doi:10.3390/IJERPH17218245

32. Ruiz-Fernández MD, Ramos-Pichardo JD, Ibáñez-Masero O, CabreraTroya J, Carmona-Rega MI, Ortega-Galán ÁM. Compassion fatigue, burnout, compassion satisfaction and perceived stress in healthcare professionals during the COVID-19 health crisis in Spain. J Clin Nurs. 2020;29(21-22):4321-4330. doi:10.1111/jocn.15469

33. Kalateh Sadati A, Zarei L, Shahabi S, et al. Nursing experiences of COVID-19 outbreak in Iran: a qualitative study. Nurs Open. 2021;8 (1):72-79. doi:10.1002/nop2.604

34. Galehdar N, Toulabi T, Kamran A, Heydari H. Exploring nurses' perception about the care needs of patients with COVID-19: a qualitative study. BMC Psychiatry. 2020;20(489):1-9. doi:10.1186/s12888-020-02898-1

35. Sayburn A. Covid-19: PHE upgrades PPE advice for all patient contacts with risk of infection. BMJ. 2020;369:m1391. doi:10.1136/ bmj.m1391 
36. Sallquist J, Eisenberg N, French DC. Indonesian adolescents 'spiritual and religious experiences and their longitudinal relations with socioemotional functioning. Dev Psychol. 2010;46(3):699-716. doi:10.1037/a0018879

37. Koenig HG. Maintaining health and well-being by putting faith into action during the COVID-19 pandemic. $J$ Relig Health. 2020;59:2205-2214. doi:10.1007/s10943-020-01035-2

38. Dein S, Loewenthal K, Lewis CA, Pargament KI. COVID-19, mental health and religion: an agenda for future research. Ment Heal Relig Cult. 2020;23(1):1-9. doi:10.1080/13674676.2020.1768725

39. Fang XH, Wu L, Lu LS, et al. Mental health problems and social supports in the COVID-19 healthcare workers: a Chinese explanatory study. BMC Psychiatry. 2021;21(34):1-8. doi:10.1186/s12888-02002998-y
40. Grey I, Arora T, Thomas J, Saneh A, Tomhe P, Abi-habib R. The role of perceived social support on depression and sleep during the COVID-19 pandemic. Psychiatry Res. 2020;293:113452. doi:10.1016/j.psychres.2020.113452

41. Özmete E, Pak M. Social work in public health the relationship between anxiety levels and perceived social support during the pandemic of COVID-19 in Turkey. Soc Work Public Health. 2020;35 (7):603-616. doi:10.1080/19371918.2020.1808144

42. Zhu W, Wei Y, Meng X, Li J. The mediation effects of coping style on the relationship between social support and anxiety in Chinese medical staff during COVID-19. BMC Health Serv Res. 2020;20 (1):1-7. doi:10.1186/s12913-020-05871-6

\section{Publish your work in this journal}

Psychology Research and Behavior Management is an international, peer-reviewed, open access journal focusing on the science of psychology and its application in behavior management to develop improved outcomes in the clinical, educational, sports and business arenas. Specific topics covered in the journal include: Neuroscience, memory and decision making; Behavior modification and management; Clinical applications; Business and sports performance management; Social and developmental studies; Animal studies. The manuscript management system is completely online and includes a very quick and fair peer-review system, which is all easy to use. Visit http://www. dovepress.com/testimonials.php to read real quotes from published authors. 